\title{
A História Econômica nas Fontes do Arquivo Nacional
}

\author{
Economic History in the Sources of the National Archives
}

\begin{abstract}
Thiago Vinicius Mantuano da Fonseca
Doutorando no Programa de Pós-Graduação em História Social da Universidade Federal Fluminense - UFF. E-mail: thiago_mantuano@id.uff.br

Marcos de Brito Monteiro Marinho

Doutorando no Programa de Pós-Graduação em História Social da Universidade Federal Fluminense - UFF. marcosmonteiromarinho@gmail.com
\end{abstract}

\section{Resumo}

Este artigo surge a partir de algumas inquietudes sobre a historiografia e o seu futuro, especialmente com as ameaças ao funcionamento do Arquivo Nacional. Para tanto, pretendemos fazer um duplo trabalho de divulgação: tanto da importância do Acervo sob guarda do Arquivo Nacional para o estabelecimento e futuro da História Econômica como campo autônomo e com vocação de síntese para a historiografia; quanto da demonstração de como os estudos e pesquisas no âmbito da História Econômica ajudaram a impulsionar o desenvolvimento da preservação, organização e demanda pela documentação no Arquivo Nacional.

Palavras-chave: História Econômica. Arquivo Nacional. Fontes.

\begin{abstract}
This article arises from some concerns about historiography and its future, especially with the threats to the functioning of the National Archives. For this, we intend to do a double work of dissemination: both the importance of the Collection under the protection of the National Archives for the establishment and future of Economic History as an autonomous field and with a vocation of synthesis for historiography; as well as the demonstration of how studies and research in the field of Economic History helped to foster the development of preservation, organization and demand for documentation in the National Archives.
\end{abstract}

Keywords: Economic History. National Archive. Sources. 
A percepção de que um texto sobre a relação da História Econômica com suas fontes guardadas no Arquivo Nacional era necessário se deu quando, na preparação para o XII Congresso Brasileiro de História Econômica, fizemos a leitura coletiva de uma interessante entrevista de Eulália Lobo para Ângela de Castro Gomes e Ronaldo Vainfas (GOMES; VAINFAS, 1992). Realizada há exatos 25 anos, meses antes da realização do Congresso inaugural da série (sediado na USP, em 1993) e da fundação da Associação Brasileira de Pesquisadores em História Econômica, associação esta que Eulália era fundadora e grande entusiasta, a leitura desta entrevista foi ao mesmo tempo alentadora e preocupante. Junto a esta leitura, se somou a grande preocupação dos autores pela atual situação do Arquivo Nacional, tanto com relação aos importantes documentos que guarda, quanto pela situação social a qual estão expostos os seus funcionários pelo atual e ilegítimo governo federal.

Voltando à entrevista de Eulália, ressaltamos os receios da professora quanto a duas tendências que se revelavam ascendentes na historiografia da época: a rejeição à factualidade empírica, mesmo que analiticamente matizada; e a crescente onda de desprezo às temáticas em torno das estruturas econômicas-sociais, assim como de seus processos históricos para situar temáticas não exclusivamente econômicas. E o que isto tem a ver com o Arquivo Nacional e sua extensa gama de serviços? Acontece é que o quadro que preocupava Eulália levava (ou levaria) a um esvaziamento das instituições arquivísticas por parte dos historiadores. Certamente que o Arquivo Nacional sofria um "virar de costas" relativo por parte dos historiadores naquela época, mas este fenômeno não se verificou em definitivo. Parte de nossos objetivos aqui é difundir o papel que os historiadores da(s) economia(s) tem desempenhado no sentido de habitar o Arquivo Nacional e, consequentemente, colaborar com sua vitalidade.

O desejo de Eulália era o retorno de uma "história compiladora", tal qual a que era praticada por seus mestres. Havia, ainda, uma preocupação: estava em voga um novo tipo historiográfico que ignorava processos como o da industrialização, que deixava de lado a formação mais geral e necessária para que os professores pudessem lecionar a história como síntese das sociedades. Como veremos, o campo da História Econômica foi o bastião contra esta tendência, e as fontes do Arquivo Nacional funcionaram como verdadeiro arsenal para os pesquisadores do campo. 


\title{
2. O Nosso Modo de Escrever Sobre História
}

Antes de adentrarmos na especificidade das fontes do Arquivo Nacional que nos subsidiam, é necessário esclarecer no que consiste a História Econômica. O nosso modo de escrever sobre História está baseado em dois aspectos primordiais: 1) os estudos de longa duração que buscam capturar as mudanças e continuidades na história de determinada sociedade; e 2) a ligação de seus objetivos com análises sintéticas, o que engloba fatores extra econômicos e o diálogo permanente com outros campos da história, das ciências sociais e da economia. Como preconizou Fontana:

\begin{abstract}
Recuperar la identidad del trabajo en el campo de la historia económica significa recordar que esta no es ni una rama de la ciencia económica, ni una variedad temática de la historia - como la historia militar o la historia de la Iglesia -, sino, en todo caso, un modo de hacer historia. De la economía se distingue por estudiar el tiempo largo y la complejidad; de las diferentes especializaciones de la historia, por el hecho de que no se limita a analizar las actividades económicas aisladamente, sino que las sitúa en un contexto más amplio, con la intención de explicar la naturaleza de los hechos sociales [...] (FONTANA, 2012, p. 25-26)
\end{abstract}

A história "invade" a economia dando nexo explicativo, muitas vezes por fora de processos que se imaginam estritamente econômicos, tais como as transformações e combinações entre as dimensões da produção, distribuição, financiamento e consumo. Desta forma, necessitamos da longa duração e da complexidade social, para termos uma análise que confere sentido ao processo histórico. Os economistas, por sua vez, optam pelas análises de curta duração de fenômenos estritamente econômicos para embasar as opções de tomada de decisão mais adequadas pelos agentes em questão. Como esclarece Hobsbawm:

\footnotetext{
O estudo dos mecanismos econômicos estava divorciado do estudo dos fatores sociais e de outros fatores que condicionam o comportamento dos agentes que constituem tais mecanismos. Foi isso que há muito tempo Maurice Dobb quis dizer em Cambridge. (HOBSBAWM, 2013, p. 152)

Para os historiadores, o interesse dessas análises reside no esclarecimento que oferecem sobre o mecanismo de transformação econômica nas circunstâncias específicas nas quais, historicamente, ocorreu ou deixou de acontecer. Naturalmente isso inclui a longa era anterior à Revolução Industrial, que obviamente é apenas de interesse periférico para a maioria dos economistas, inclusive os do desenvolvimento. (HOBSBAWM, 2013, p. 174-175)
}

Acreditamos na história como um instrumento que possibilite a análise tão sintética e generalizante, quanto específica e complexa de uma sociedade pretérita. Desta forma, o processo de constante aproximação com a expressão da realidade material e histórica estão refletidos nos resultados apresentados pelas melhores pesquisas deste campo. Para tal, é fundamental que haja um conjunto de documentos farto e coerentemente selecionado, que nos permita confirmar ou refutar as hipóteses de pesquisa. 
Com o intuito de justificar esse posicionamento é necessário que o trabalho responda às problemáticas de tipo econômico: o que produzir? Como produzir? Como distribuir o que se produziu? Essas são as principais e mais básicas questões da economia, elas norteiam as nossas pesquisas e estão refletidas em nossos textos. Entretanto, temos o viés do historiador, e por isso privilegiamos a longa duração, a complexidade social, cultural e política da sociedade a ser analisada (CIPOLLA, 1993).

Para além de fatos econômicos isolados, devemos multiplicar esforços no sentido de entender os sistemas, os modos e processos de produção, as diferentes estruturas e conjunturas para que possamos identificar objetivos, as infraestruturas, e explicar as operações e funcionamento de agentes, empresas, instituições, bem como a atuação das classes sociais a elas vinculadas. Neste sentido, o acervo do Arquivo Nacional é essencial, pois nos fornece valiosas informações dos processos econômicos e não econômicos, mesmo que possamos entendê-los como conexos e basilares à análise. Seguindo Ciro Cardoso e Hector Brignoli, os investigadores da História Econômica devem ir "Do acontecimento à estrutura; da curta à longa duração; do individual ao coletivo; em todos os planos considerados será fácil constatar o processo de ampliação e aprofundamento que caracteriza a visão atual da história." (CARDOSO; BRIGNOLI, 1981). Este modo de escrever sobre História nos foi legado pelo autor e está presente em nossos trabalhos.

O arranque da história econômica na Europa se deu na década de 1930, a partir da maior crise econômica global do capitalismo até o presente momento; já no Brasil, os estudos de Caio Prado Júnior e Celso Furtado, a partir da década de 1940, dão início à área que segue fecunda até hoje. Por isso, discordamos frontalmente de Florentino e Fragoso sobre um suposto “[...] abandono da reflexão e da própria pesquisa em história econômica." (FRAGOSO; FLORENTINO, 1997, p. 31).

Embora já tenha havido outros períodos de renovação da História Econômica, é importante destacarmos que o presente momento é o de ampliar seus estudos e pesquisas. $\mathrm{O}$ avanço científico que, ao mesmo tempo e com propriedade, faz a crítica aos trabalhos clássicos e os retoma de maneira criativa, não descarta os pressupostos que ainda não foram superados. Um deles é o de que: "Não há mais, verdadeiramente, no mundo contemporâneo, história econômica deste ou daquele país, mas unicamente a de toda a humanidade." (PRADO, 1972, p. 213). 
Isto não significa dizer que o estudo do capitalismo encerra o campo de estudos da História Econômica. Este é, provavelmente, o maior erro metodológico dos historiadores que passaram a entender a economia de forma retrospectiva. Com gosto pelas fontes e pela exposição diacrônica, a chamada Nova História Econômica transportou algumas categorias capitalistas para o passado e deu de ombros para a transformação histórica, trazendo graves prejuízos para o campo. Aqui fica um alerta importante: os historiadores da economia devem ocupar os arquivos, mas analisar com responsabilidade a documentação é tão importante quanto o seu levantamento. (HOBSBAWM, 2013).

As descobertas empíricas dos trabalhos da Nova História Econômica - de agora em diante NHE - são sugestivas, mas encontram-se engessadas pelo próprio aporte teórico abraçado: uma concepção formal de economia que desconsidera a variedade de formas pelas quais as sociedades asseguram sua subsistência. A NHE adota uma abordagem cuja validade, supostamente, é universal: o princípio da escassez e seus efeitos sobre as ações humanas. A escassez de meios para que se atinja determinados fins impõe o comportamento racional ao ser humano, que calcula sistematicamente o modo através do qual pode satisfazer sua necessidade - os fins - empregando o menos possível em termos de recursos - os meios (TOMICH, 2016, p. 59-61). As unidades de ação econômica - empresas, grupos, indivíduos - operam, em todas as sociedades humanas, sob esta a mesma lógica. Deste modo, a produção é tida como elemento periférico, pois terra, trabalho e capital são considerados como universais abstratos, passíveis de serem quantificados de maneira descolada da realidade para que os analistas possam contabilizar a relação meios/fins. Para a NHE, estes conceitos adquirem estatuto de lei matemática, de modo a configurar uma explicação teleológica da história da humanidade.

Entretanto, o problema está menos nos métodos quantitativos do que na postura teórica usada para interpretar os dados. Isto porque se considerarmos a explicação da NHE como algo inerente à quantificação e à seriação, corremos o risco de cair em um outro extremo, que é fazer uma história absolutamente não quantificável. Este é o caso de Sidney Chalhoub que, ao trabalhar com os processos criminais do próprio Arquivo Nacional, não se preocupa em medir a representatividade da maior parte dos casos por ele analisado. E isto não é um descuido, mas sim sua proposta metodológica, que reside apenas no trabalho com "interpretações de interpretações", ou seja, observar o que aqueles indivíduos - uma centena de escravos e libertos, bem como algumas dezenas de senhores - dos casos por ele analisados entendiam por escravidão ou liberdade (CHALHOUB, 1990, p. 251). 
Com este panorama epistemológico e metodológico podemos perceber que, acertada ou equivocadamente, os modos de fazer da História Econômica são absolutamente dependentes de fontes de informações que tem por guarda, tipicamente, não a memória, mas instituições, empresas, organizações, etc. As instituições que possuem a custódia de extensa documentação podem ter fim próprio para tal, prezando pela segurança e garantia de acesso à informação, ou podem possuir um arquivo corrente/histórico como parte subsidiária de suas atividades-fim ou de sua "política de memória". Por conta dessa exigência basilar que caracteriza o trabalho do historiador da economia, intenso e diverso em termos de elementos empíricos, e da multiplicidade de entidades possuem tais fontes que a existência de uma Ciência da Informação, produtora de importantes avanços no desenvolvimento da gestão informacional, é fundamental. A garantia e a prontidão do acesso às fontes é a principal responsável pela autonomia de nossa disciplina.

\section{Os arquivos democráticos como garantidores das pesquisas em História Econômica}

O acesso/utilização da documentação que viabiliza a construção científica do seu ofício é uma grande preocupação entre os historiadores. No que tange aos pesquisadores em História Econômica, esta questão é agravada pelo o fato do sigilo de muitas informações necessárias ao nosso trabalho estar ligado a interesses econômicos múltiplos, desde os estatais até os mais particulares, empresariais ou familiares.

Stiglitz, há muito, tem encarado a questão da transparência e da segurança/disponibilização de informações como fundamental, não apenas para o avanço da ciência econômica, mas como poderoso instrumento democrático e de combate às desigualdades.

Assim como as assimetrias de informação dão aos controladores o poder de perseguir objetivos que são mais de seu próprio interesse do que dos acionistas, o mesmo ocorre com as autoridades públicas tomadoras de decisões, que podem impor políticas que são mais de seu interesse do que dos cidadãos (STIGLITZ, 2002, p. 27-281 apud LOPES, 2007, p. 8).

Para os historiadores da economia isto está dramaticamente demarcado. Em nossa frágil democracia, por diversas vezes, os governos não têm interesse em um passado que parece remoto, mas que marca profundamente a atual estrutura produtiva, financeira, distributiva e de

\footnotetext{
${ }^{1}$ STIGLITZ, Joseph. Transparency in government, in the right to tell: the role of mass media in economic
} development. Washington: World Bank, 2001. 
consumo das sociedades. Por outro lado, as empresas pouco colaboram para descortinar o seu passado de forma crítica, por mais que possuam programas de memória institucional/empresarial, e não contribuem para a reflexão sobre como se estabeleceram e cresceram em determinada sociedade.

$\mathrm{Na}$ contramão disto, a Ciência da Informação se desenvolveu como ferramenta de cidadania e importante garantia para o desenvolvimento científico de diversos campos do saber. Num mundo cada vez mais em rede, a utilização da tecnologia da informação casou-se com seus objetivos de forma quase que instintiva. Maria Odila Fonseca, em suas últimas reflexões sobre a garantia/expansão do uso do documento de arquivo, bem como sobre o diálogo entre arquivistas e usuários de arquivos, elaborou aquilo que parece o seu mais importante legado: pensar um serviço de informação orientado ao usuário, com modelos baseados em critérios que atendam ao cidadão que busca a informação. Com estas orientações, a professora Odila buscava ultrapassar os modelos referenciados nos diferentes usos da informação, pois estes poderiam ser instrumentalizados politicamente para vetar alguns usos específicos da informação. Segundo esta importante arquivista brasileira,

Um serviço de informação orientado ao usuário implica em se considerar o usuário e
o impacto da informação sobre sua vida, inclusive fora dos espaços físicos dos
serviços de informação. Hoje a informação encontra-se crescentemente "on-line", fora
do ambiente tradicional dos serviços de informação. É a primazia de um não lugar, a
Internet, sobre os lugares tradicionais de gestão e transferência da informação como
os serviços e instituições arquivísticas. Assim, um serviço de informação centrado no
usuário explicita institucionalmente seus objetivos de atender às necessidades de
informação deste. A tomada de decisões relativas ao planejamento e à gestão é
orientada sob esta perspectiva. (FONSECA; JARDIM, 2004, p. 2)

Acreditamos que essa diretriz tem sido seguida pelos servidores do Arquivo Nacional. Pensamos nesta instituição como um “[...] centro de arquivos, que é um sistema pluricelular criado especialmente para incorporar, salvaguardar e divulgar qualquer arquivo desactivado ou ainda para incorporar informação sem interesse administrativo (valor primário) proveniente de organismos em plena actividade.” (RIBEIRO, 2011, p. 13). Somando as características institucionais e potencialidades de um arquivo como o Nacional ao novo paradigma adotado de sistema de informação centrado no usuário e, especialmente, à extrema qualificação de seus funcionários, consideramos que, a despeito dos diversos problemas que ocorrem devido ao desinvestimento e redução forçada do custeio por parte do poder público, a importante documentação sob guarda do Arquivo Nacional tem sua consulta viabilizada de forma segura e crescentemente facilitada. 
Neste sentido, é importante frisar o trabalho organizativo, de identificação e disponibilização que tem sido feito em projetos de suma importância para os historiadores da economia como o Acervo do Judiciário, o Entrada de Estrangeiros no Brasil e o Mapa Memória da Administração Pública Brasileira. Segundo a servidora Dilma Cabral, esses projetos atuam

[...] conciliando a guarda e a preservação de significativo patrimônio documental e a ampliação dos serviços de acesso à informação. Se a importância da pesquisa histórica no universo das instituições arquivísticas esteve sempre relacionada a um dos fundamentos desta disciplina, o princípio de respeito aos fundos, novos elementos, como o esforço de normalização dos procedimentos e a criação de sistemas e bases de dados unificadas de instrumentos de pesquisa, reforçaram seu papel no tratamento e na qualidade da informação pública prestada ao usuário. (SÁ NETTO, 2011, p. 6)

No Quadro 1 listamos um criterioso conjunto de fundos do Arquivo Nacional tradicionalmente pesquisados pela historiografia econômica brasileira. Na próxima seção, forneceremos um panorama sobre uma série e quatro fundos de especial valia para as pesquisas no âmbito da História Econômica. Junto a este panorama, faremos algumas sugestões metodológicas que combinem ambas as formas de análise - a quantitativa e a qualitativa, embora nunca com concepções teóricas próximas às da NHE ou às de Chalhoub.

Quadro 1: Fundos de especial interesse para História Econômica no Arquivo Nacional

\begin{tabular}{|c|c|c|c|}
\hline FUNDO & CÓDIGO & $\begin{array}{c}\text { DOCUMENTAÇÃO } \\
\text { (ESPÉCIES) } \\
\text { PRINCIPAL(AIS) }\end{array}$ & $\begin{array}{c}\text { RECORTE } \\
\text { TEMÁTICO E } \\
\text { CRONOLÓGICO }\end{array}$ \\
\hline $\begin{array}{l}\text { Administração do Porto } \\
\text { do Rio de Janeiro }\end{array}$ & BR RJANRIO 01 & $\begin{array}{c}\text { Textual (Contábil, Financeiro, } \\
\text { Pessoal, Periódicos, Relatórios, } \\
\text { Projetos, Atas, etc.), Cartografia e } \\
\text { Fotografia }\end{array}$ & $\begin{array}{l}\text { Transportes; Brasil } \\
\text { República }\end{array}$ \\
\hline Agência Nacional & BR RJANRIO EH & $\begin{array}{c}\text { Fotografia, Filmografia, } \\
\text { Fonografia e Sonoras }\end{array}$ & $\begin{array}{l}\text { Economia Política; } \\
\text { Brasil República }\end{array}$ \\
\hline Agricultura & BR RJANRIO DB & $\begin{array}{c}\text { Textual (Atas, Projetos, Relatórios, } \\
\text { Legislação, Decisões, etc.) e } \\
\text { Cartografia }\end{array}$ & $\begin{array}{l}\text { Agrário; Escravidão; } \\
\text { Economia Política; } \\
\text { Brasil Império; Brasil } \\
\text { República }\end{array}$ \\
\hline André Pinto Rebouças & BR RJANRIO OW & $\begin{array}{c}\text { Textual (Diários, Anotações, } \\
\text { Cartas, Projetos, Requerimentos, } \\
\text { Publicações, Periódicos, etc.) e } \\
\text { Cartografia }\end{array}$ & $\begin{array}{l}\text { Urbano; Transportes; } \\
\text { Empresas; Escravidão; } \\
\text { Brasil Império }\end{array}$ \\
\hline $\begin{array}{c}\text { Banco Central Brasileiro } \\
\text { Sociedade Anônima }\end{array}$ & BR RJANRIO T0 & $\begin{array}{l}\text { Textual (Financeira, Relatórios, } \\
\text { Atas, Legislação, etc.) }\end{array}$ & $\begin{array}{c}\text { Financeiro; Economia } \\
\text { Política; Brasil } \\
\text { República } \\
\end{array}$ \\
\hline $\begin{array}{c}\text { Banco Nacional de } \\
\text { Desenvolvimento } \\
\text { Econômico e Social } \\
\end{array}$ & BR DFANBSB AA6 & $\begin{array}{l}\text { Textual (Financeira, Relatórios, } \\
\text { Atas, Legislação, Balanços etc.) }\end{array}$ & $\begin{array}{l}\text { Financeiro; Economia } \\
\text { Política; Brasil } \\
\text { República }\end{array}$ \\
\hline $\begin{array}{c}\text { Bolsa de Valores do Rio } \\
\text { de Janeiro }\end{array}$ & BR RJANRIO P8 & $\begin{array}{l}\text { Textual (Financeira, Relatórios, } \\
\text { Atas, Estatísticas, etc.) }\end{array}$ & $\begin{array}{l}\text { Financeiro; Brasil } \\
\text { Império; Brasil } \\
\text { República }\end{array}$ \\
\hline Brasões & BR RJANRIO 0D & Textual (Prosopografia) & $\begin{array}{l}\text { Social; Brasil Colônia; } \\
\text { Brasil Império; Brasil } \\
\text { República }\end{array}$ \\
\hline
\end{tabular}




\begin{tabular}{|c|c|c|c|}
\hline Casa da Moeda do Brasil & BR RJANRIO 0K & $\begin{array}{l}\text { Textual (Relatórios, Atas, } \\
\text { Legislação, etc.) }\end{array}$ & $\begin{array}{c}\text { Financeiro; Brasil } \\
\text { Império; Brasil } \\
\text { República }\end{array}$ \\
\hline $\begin{array}{l}\text { Comissão Construtora da } \\
\text { Avenida Central }\end{array}$ & BR RJANRIO 1C & $\begin{array}{l}\text { Textual (Projetos, Relatórios, } \\
\text { Legislação, Pessoal, etc.), } \\
\text { Cartografia e Fotografia }\end{array}$ & $\begin{array}{l}\text { Urbano; Transportes; } \\
\text { Brasil República }\end{array}$ \\
\hline $\begin{array}{c}\text { Comissão de Valores } \\
\text { Mobiliários } \\
\end{array}$ & BR RJANRIO T2 & $\begin{array}{c}\text { Textual (Financeira, Relatórios, } \\
\text { Atas, etc.) }\end{array}$ & $\begin{array}{c}\text { Financeiro; Brasil } \\
\text { República }\end{array}$ \\
\hline $\begin{array}{c}\text { Companhia de } \\
\text { Navegação Lloyd } \\
\text { Brasileiro } \\
\end{array}$ & BR RJANRIO LD & $\begin{array}{c}\text { Textual (Contábil, Financeiro, } \\
\text { Pessoal, Periódicos, Relatórios, } \\
\text { Projetos, etc.) e Fotografia }\end{array}$ & $\begin{array}{c}\text { Transportes; Indústria; } \\
\text { Empresas; Brasil } \\
\text { República } \\
\end{array}$ \\
\hline $\begin{array}{l}\text { Companhia Docas do } \\
\text { Estado de São Paulo }\end{array}$ & BR DFANBSB PA & $\begin{array}{c}\text { Textual (Contábil, Financeiro, } \\
\text { Pessoal, Periódicos, Relatórios, } \\
\text { Projetos, Atas, etc.), Cartografia e } \\
\text { Fotografia }\end{array}$ & $\begin{array}{l}\text { Transportes; Empresas; } \\
\text { Brasil República }\end{array}$ \\
\hline $\begin{array}{c}\text { Companhia Docas do Rio } \\
\text { de Janeiro }\end{array}$ & BR DFANBSB Z9 & $\begin{array}{c}\text { Textual (Contábil, Financeiro, } \\
\text { Pessoal, Periódicos, Relatórios, } \\
\text { Projetos, Atas, etc.), Cartografia e } \\
\text { Fotografia }\end{array}$ & $\begin{array}{l}\text { Transportes; Empresas; } \\
\text { Brasil República }\end{array}$ \\
\hline $\begin{array}{c}\text { Companhia } \\
\text { Radiotelegráfica } \\
\text { Brasileira }\end{array}$ & BR RJANRIO PF & $\begin{array}{c}\text { Textual (Contábil, Financeiro, } \\
\text { Pessoal, Periódicos, Relatórios, } \\
\text { Projetos, Atas, etc.), Cartografia e } \\
\text { Fotografia }\end{array}$ & $\begin{array}{l}\text { Comunicações; } \\
\text { Empresas; Brasil } \\
\text { República }\end{array}$ \\
\hline Conselho de Estado & BR RJANRIO 1R & $\begin{array}{c}\text { Textual (Periódicos, Relatórios, } \\
\text { Projetos, Atas, etc.) }\end{array}$ & $\begin{array}{l}\text { Economia Política; } \\
\text { Brasil Império }\end{array}$ \\
\hline Corte de Apelação & BR RJANRIO 20 & $\begin{array}{c}\text { Textual (Processos, Acórdãos, } \\
\text { Decisões, etc.) }\end{array}$ & $\begin{array}{l}\text { Judiciário; Brasil } \\
\text { Império }\end{array}$ \\
\hline Cristiano Benedito Otoni & BR RJANRIO SY & $\begin{array}{l}\text { Textual (Diários, Anotações, } \\
\text { Cartas, Projetos, Requerimentos, } \\
\text { Publicações, Periódicos, etc.) }\end{array}$ & $\begin{array}{l}\text { Empresas; Brasil } \\
\text { Império }\end{array}$ \\
\hline $\begin{array}{l}\text { Departamento } \\
\text { Administrativo do } \\
\text { Serviço Público }\end{array}$ & BR RJANRIO 2C & $\begin{array}{c}\text { Textual, Cartografia, Iconografia, } \\
\text { Sonoras, etc. }\end{array}$ & $\begin{array}{l}\text { Economia Política; } \\
\text { Brasil República }\end{array}$ \\
\hline $\begin{array}{c}\text { Departamento Nacional } \\
\text { do Café }\end{array}$ & RJANRIO T6 & $\begin{array}{c}\text { Textual (Circulares, Comunicados, } \\
\text { Atas, Ordens, Resoluções, } \\
\text { Legislação, etc.) }\end{array}$ & $\begin{array}{l}\text { Agrário; Economia } \\
\text { Política; Brasil } \\
\text { República }\end{array}$ \\
\hline Diretoria dos Correios & BR RJANRIO OF & $\begin{array}{c}\text { Textual (Contábil, Financeiro, } \\
\text { Pessoal, Periódicos, Relatórios, } \\
\text { Projetos, Atas, etc.), Cartografia e } \\
\text { Fotografia }\end{array}$ & $\begin{array}{l}\text { Comunicações; } \\
\text { Empresas; Brasil } \\
\text { República }\end{array}$ \\
\hline $\begin{array}{c}\text { Divisão de Polícia } \\
\text { Marítima, Aérea e de } \\
\text { Fronteiras } \\
\end{array}$ & BR RJANRIO OL & Textual (Relações e Registros) & $\begin{array}{l}\text { Imigração; Brasil } \\
\text { Império; Brasil } \\
\text { República }\end{array}$ \\
\hline $\begin{array}{l}\text { Empresa de Portos do } \\
\text { Brasil Sociedade } \\
\text { Anônima }\end{array}$ & BR DFANBSB TR & $\begin{array}{c}\text { Textual (Contábil, Financeiro, } \\
\text { Pessoal, Periódicos, Relatórios, } \\
\text { Projetos, Atas, etc.), Cartografia e } \\
\text { Fotografia }\end{array}$ & $\begin{array}{l}\text { Transportes; Brasil } \\
\text { República }\end{array}$ \\
\hline Eusébio de Queirós & BR RJANRIO PM & $\begin{array}{c}\text { Textual (Diários, Anotações, } \\
\text { Cartas, Projetos, Requerimentos, } \\
\text { Publicações, Periódicos, } \\
\text { Legislação, etc.) }\end{array}$ & $\begin{array}{l}\text { Escravidão; Brasil } \\
\text { Império }\end{array}$ \\
\hline $\begin{array}{c}\text { Fazenda Nacional de } \\
\text { Santa Cruz }\end{array}$ & BR RJANRIO EM & $\begin{array}{c}\text { Textual, Cartografia, Iconografia, } \\
\text { etc. }\end{array}$ & $\begin{array}{l}\text { Agrário; Escravidão; } \\
\text { Brasil Império }\end{array}$ \\
\hline $\begin{array}{l}\text { Inspetoria Geral das } \\
\text { Terras e Colonização }\end{array}$ & BR RJANRIO 3D & $\begin{array}{c}\text { Textual, Cartografia, Iconografia, } \\
\text { etc. }\end{array}$ & $\begin{array}{l}\text { Agrário; Imigração; } \\
\text { Brasil Império; Brasil } \\
\text { República }\end{array}$ \\
\hline $\begin{array}{l}\text { Instituto Brasileiro de } \\
\text { Análises Sociais e } \\
\text { Econômicas }\end{array}$ & BR RJANRIO HA & $\begin{array}{l}\text { Textual (Panfletos, Periódicos, } \\
\text { Estudos, Relatórios e Demais } \\
\text { Publicações) e Iconografia }\end{array}$ & $\begin{array}{l}\text { Economia Política; } \\
\text { Brasil República }\end{array}$ \\
\hline
\end{tabular}




\begin{tabular}{|c|c|c|c|}
\hline $\begin{array}{l}\text { Instituto Brasileiro do } \\
\text { Café }\end{array}$ & BR RJANRIO N9 & $\begin{array}{c}\text { Textual (Circulares, Comunicados, } \\
\text { Atas, Ordens, Resoluções, } \\
\text { Legislação, etc.) }\end{array}$ & $\begin{array}{l}\text { Agrário; Economia } \\
\text { Política; Brasil } \\
\text { República } \\
\end{array}$ \\
\hline $\begin{array}{l}\text { Instituto de Pesquisa } \\
\text { Econômica Aplicada }\end{array}$ & BR DFANBSB DO & $\begin{array}{c}\text { Textual (Panfletos, Periódicos, } \\
\text { Estudos, Relatórios e Demais } \\
\text { Publicações) e Iconografia }\end{array}$ & $\begin{array}{l}\text { Economia Política; } \\
\text { Brasil República }\end{array}$ \\
\hline $\begin{array}{c}\text { Instituto do Açúcar e do } \\
\text { Álcool }\end{array}$ & BR RJANRIO IY & $\begin{array}{c}\text { Textual (Circulares, Comunicados, } \\
\text { Atas, Ordens, Resoluções, } \\
\text { Legislação, etc.) }\end{array}$ & $\begin{array}{l}\text { Agrário; Economia } \\
\text { Política; Brasil } \\
\text { República } \\
\end{array}$ \\
\hline $\begin{array}{l}\text { Instituto Nacional do } \\
\text { Mate }\end{array}$ & BR RJANRIO 3F & $\begin{array}{c}\text { Textual (Circulares, Comunicados, } \\
\text { Atas, Ordens, Resoluções, } \\
\text { Legislação, etc.) }\end{array}$ & $\begin{array}{l}\text { Agrário; Economia } \\
\text { Política; Brasil } \\
\text { República }\end{array}$ \\
\hline Instituto Nacional do Sal & BR RJANRIO 3G & $\begin{array}{c}\text { Textual (Circulares, Comunicados, } \\
\text { Atas, Ordens, Resoluções, } \\
\text { Legislação, etc.) } \\
\end{array}$ & $\begin{array}{l}\text { Agrário; Economia } \\
\text { Política; Brasil } \\
\text { República } \\
\end{array}$ \\
\hline $\begin{array}{l}\text { Juízo da Provedoria do } \\
\text { Rio de Janeiro } \\
\end{array}$ & BR RJANRIO ZJ & $\begin{array}{c}\text { Textual (Processos, Acórdãos, } \\
\text { Decisões, etc.) }\end{array}$ & $\begin{array}{c}\text { Judiciário; Brasil } \\
\text { Império }\end{array}$ \\
\hline $\begin{array}{c}\text { Juízo de Direito do } \\
\text { Comércio - Coleção } \\
\text { Processos Comerciais }\end{array}$ & BR RJANRIO NA & $\begin{array}{c}\text { Textual (Processos, Acórdãos, } \\
\text { Decisões, etc.) }\end{array}$ & $\begin{array}{l}\text { Judiciário; Comércio; } \\
\text { Empresas; Brasil } \\
\text { Império; Brasil } \\
\text { República }\end{array}$ \\
\hline $\begin{array}{c}\text { Juízo de Órfãos e } \\
\text { Ausentes }\end{array}$ & $\begin{array}{c}\text { BR RJANRIO ZN ZL } \\
\text { ZM }\end{array}$ & $\begin{array}{c}\text { Textual (Processos, Acórdãos, } \\
\text { Decisões, Inventários, } \\
\text { Testamentos, etc.) } \\
\end{array}$ & $\begin{array}{c}\text { Judiciário; Social; Brasil } \\
\text { Império; Brasil } \\
\text { República } \\
\end{array}$ \\
\hline $\begin{array}{c}\text { Juízo dos Feitos da } \\
\text { Fazenda Nacional do Rio } \\
\text { de Janeiro } \\
\end{array}$ & BR RJANRIO 3Z & $\begin{array}{c}\text { Textual (Processos, Acórdãos, } \\
\text { Decisões, etc.) }\end{array}$ & $\begin{array}{c}\text { Judiciário; Tributário; } \\
\text { Brasil Império; Brasil } \\
\text { República } \\
\end{array}$ \\
\hline $\begin{array}{l}\text { Juízo Especial do } \\
\text { Comércio do Rio de } \\
\text { Janeiro }\end{array}$ & BR RJANRIO JC JD & $\begin{array}{l}\text { Textual (Processos, Acórdãos, } \\
\text { Decisões, etc.) }\end{array}$ & $\begin{array}{l}\text { Judiciário; Comércio; } \\
\text { Empresas; Brasil } \\
\text { Império; Brasil } \\
\text { República }\end{array}$ \\
\hline $\begin{array}{l}\text { Junta Comercial do Rio } \\
\text { de Janeiro }\end{array}$ & BR RJANRIO 46 & $\begin{array}{c}\text { Textual (Registros, Atas, } \\
\text { Contratos, Estatutos, Estatísticas, } \\
\text { Contábil, Financeiro, Processos, } \\
\text { etc.) }\end{array}$ & $\begin{array}{l}\text { Comércio; Empresas; } \\
\text { Brasil Império; Brasil } \\
\text { República }\end{array}$ \\
\hline $\begin{array}{c}\text { Junta do Comércio, } \\
\text { Agricultura, Fábricas e } \\
\text { Navegação }\end{array}$ & - BR RJANRIO 7X & $\begin{array}{c}\text { Textual (Registros, Atas, } \\
\text { Contratos, Estatutos, Estatísticas, } \\
\text { Contábil, Financeiro, Processos, } \\
\text { Decisões, Legislação, etc.) }\end{array}$ & $\begin{array}{l}\text { Comércio; Empresas; } \\
\text { Brasil Colônia; Brasil } \\
\text { Império }\end{array}$ \\
\hline $\begin{array}{l}\text { Ministério da Agricultura, } \\
\text { Comércio e Obras } \\
\text { Públicas }\end{array}$ & BR RJANRIO 4M & $\begin{array}{c}\text { Textual, Cartografia, Iconografia, } \\
\text { etc. }\end{array}$ & $\begin{array}{c}\text { Agrário; Comércio; } \\
\text { Urbano; Economia } \\
\text { Política; Brasil Império }\end{array}$ \\
\hline Ministério da Fazenda & BR RJANRIO 4O & $\begin{array}{l}\text { Textual, Cartografia, Iconografia, } \\
\text { etc. }\end{array}$ & $\begin{array}{l}\text { Economia Política; } \\
\text { Brasil República }\end{array}$ \\
\hline $\begin{array}{c}\text { Ministério da Indústria e } \\
\text { Comércio }\end{array}$ & BR DFANBSB HB & $\begin{array}{l}\text { Textual, Cartografia, Iconografia, } \\
\text { etc. }\end{array}$ & $\begin{array}{l}\text { Economia Política; } \\
\text { Brasil República }\end{array}$ \\
\hline $\begin{array}{l}\text { Ministério da Indústria, } \\
\text { Viação e Obras Públicas }\end{array}$ & BR RJANRIO 4Q & $\begin{array}{l}\text { Textual, Cartografia, Iconografia, } \\
\text { etc. }\end{array}$ & $\begin{array}{l}\text { Economia Política; } \\
\text { Brasil República }\end{array}$ \\
\hline $\begin{array}{l}\text { Ministério da Justiça e } \\
\text { Negócios Interiores }\end{array}$ & BR RJANRIO 4T & $\begin{array}{l}\text { Textual, Cartografia, Iconografia, } \\
\text { etc. }\end{array}$ & $\begin{array}{l}\text { Economia Política; } \\
\text { Brasil Império }\end{array}$ \\
\hline $\begin{array}{l}\text { Ministério da Viação e } \\
\text { Obras Públicas } \\
\end{array}$ & BR RJANRIO 4Y & $\begin{array}{l}\text { Textual, Cartografia, Iconografia, } \\
\text { etc. }\end{array}$ & $\begin{array}{l}\text { Economia Política; } \\
\text { Brasil República }\end{array}$ \\
\hline $\begin{array}{c}\text { Ministério das Minas e } \\
\text { Energia }\end{array}$ & BR DFANBSB DT & $\begin{array}{l}\text { Textual, Cartografia, Iconografia, } \\
\text { etc. }\end{array}$ & $\begin{array}{l}\text { Economia Política; } \\
\text { Brasil República }\end{array}$ \\
\hline Ministério do Império & BR RJANRIO 53 & $\begin{array}{l}\text { Textual, Cartografia, Iconografia, } \\
\text { etc. }\end{array}$ & $\begin{array}{l}\text { Economia Política; } \\
\text { Brasil Império }\end{array}$ \\
\hline Ministério do Trabalho & BR DFANBSB DV & $\begin{array}{l}\text { Textual, Cartografia, Iconografia, } \\
\text { etc. }\end{array}$ & $\begin{array}{l}\text { Economia Política; } \\
\text { Brasil República }\end{array}$ \\
\hline
\end{tabular}




\begin{tabular}{|c|c|c|c|}
\hline $\begin{array}{c}\text { Ministério dos Negócios } \\
\text { do Interior }\end{array}$ & BR RJANRIO J6 & $\begin{array}{l}\text { Textual, Cartografia, Iconografia, } \\
\text { etc. }\end{array}$ & $\begin{array}{c}\text { Economia Política; } \\
\text { Brasil Império } \\
\end{array}$ \\
\hline Negócios de Portugal & BR RJANRIO 59 & $\begin{array}{l}\text { Textual, Cartografia, Iconografia, } \\
\text { etc. }\end{array}$ & $\begin{array}{l}\text { Comércio; Agrário; } \\
\text { Brasil Colônia }\end{array}$ \\
\hline $\begin{array}{l}\text { Ofício de Notas do Rio de } \\
\text { Janeiro }\end{array}$ & BR RJANRIO 5D - 5Q & Textual (Notas Cartoriais) & $\begin{array}{c}\text { Social; Comércio; } \\
\text { Urbano; Financeiro; } \\
\text { Brasil Império; Brasil } \\
\text { República }\end{array}$ \\
\hline $\begin{array}{c}\text { Ofício de Protesto de } \\
\text { Letras e Títulos do Rio de } \\
\text { Janeiro }\end{array}$ & BR RJANRIO 5R & Textual (Processos) & $\begin{array}{c}\text { Social; Comércio; } \\
\text { Urbano; Financeiro; } \\
\text { Brasil Império; Brasil } \\
\text { República }\end{array}$ \\
\hline $\begin{array}{l}\text { Ofício de Registro de } \\
\text { Imóveis do Rio de } \\
\text { Janeiro }\end{array}$ & BR RJANRIO 5V - 65 & Textual (Notas Cartoriais) & $\begin{array}{l}\text { Fundiário; Urbano; } \\
\text { Agrário; Financeiro; } \\
\text { Brasil Império; Brasil } \\
\text { República }\end{array}$ \\
\hline Percival Farquhar & BR RJANRIO SC & $\begin{array}{l}\text { Textual (Diários, Anotações, } \\
\text { Cartas, Projetos, Requerimentos, } \\
\text { Publicações, Periódicos, etc.), } \\
\text { Cartografia e Fotografia }\end{array}$ & $\begin{array}{l}\text { Urbano; Transportes; } \\
\text { Empresas; Indústria; } \\
\text { Brasil República }\end{array}$ \\
\hline Polícia da Corte & BR RJANRIO 0E & $\begin{array}{l}\text { Textual (Diligências, Inquéritos, } \\
\text { Registros, Fichas, etc.) }\end{array}$ & $\begin{array}{l}\text { Urbana; Social; } \\
\text { Escravidão; Imigração; } \\
\text { Brasil Império }\end{array}$ \\
\hline Presidência da República & BR RJANRIO DX & $\begin{array}{c}\text { Textual, Cartografia, Iconografia, } \\
\text { Fotografia, Filmografia, } \\
\text { Fonografia e Sonoras }\end{array}$ & $\begin{array}{l}\text { Economia Política; } \\
\text { Brasil República }\end{array}$ \\
\hline $\begin{array}{l}\text { Pretoria Cível do Rio de } \\
\text { Janeiro }\end{array}$ & $\begin{array}{l}\text { BR RJANRIO 6H - } \\
\text { VB3 }\end{array}$ & $\begin{array}{c}\text { Textual (Processos, Acórdãos, } \\
\text { Decisões, etc.) }\end{array}$ & $\begin{array}{c}\text { Judiciário; Brasil } \\
\text { Império; Brasil } \\
\text { República } \\
\end{array}$ \\
\hline Privilégios Industriais & BR RJANRIO PI & $\begin{array}{l}\text { Textual (Requerimentos, } \\
\text { Relatórios, Pareceres e Legislação) }\end{array}$ & $\begin{array}{l}\text { Empresas; Indústria; } \\
\text { Agrário; Urbano; Brasil } \\
\text { Império; Brasil } \\
\text { República }\end{array}$ \\
\hline $\begin{array}{l}\text { Recebedoria do Rio de } \\
\text { Janeiro }\end{array}$ & BR RJANRIO 80 & $\begin{array}{l}\text { Textual (Processos, Acórdãos, } \\
\text { Decisões, etc.) }\end{array}$ & $\begin{array}{c}\text { Judiciário; Tributário; } \\
\text { Brasil Império; Brasil } \\
\text { República } \\
\end{array}$ \\
\hline $\begin{array}{l}\text { Rede Ferroviária Federal } \\
\text { Sociedade Anônima }\end{array}$ & BR DFANBSB AQ & $\begin{array}{c}\text { Textual (Contábil, Financeiro, } \\
\text { Pessoal, Periódicos, Relatórios, } \\
\text { Projetos, Atas, etc.), Cartografia e } \\
\text { Fotografia }\end{array}$ & $\begin{array}{l}\text { Transportes; Empresas; } \\
\text { Brasil República }\end{array}$ \\
\hline Relação da Bahia & BR RJANRIO 83 & $\begin{array}{c}\text { Textual (Processos, Acórdãos, } \\
\text { Decisões, etc.) }\end{array}$ & $\begin{array}{c}\text { Judiciário; Comércio; } \\
\text { Empresas; Brasil } \\
\text { Colônia; Brasil Império }\end{array}$ \\
\hline $\begin{array}{l}\text { Relação do Rio de } \\
\text { Janeiro }\end{array}$ & BR RJANRIO 84 & $\begin{array}{l}\text { Textual (Processos, Acórdãos, } \\
\text { Decisões, etc.) }\end{array}$ & $\begin{array}{c}\text { Judiciário; Comércio; } \\
\text { Empresas; Brasil } \\
\text { Colônia; Brasil Império }\end{array}$ \\
\hline Sesmarias & BR RJANRIO BI & $\begin{array}{l}\text { Textual, Cartografia, Iconografia, } \\
\text { etc. }\end{array}$ & $\begin{array}{l}\text { Agrário; Escravidão; } \\
\text { Brasil Colônia; Brasil } \\
\text { Império } \\
\end{array}$ \\
\hline $\begin{array}{l}\text { Siderurgia Brasileira } \\
\text { Sociedade Anônima }\end{array}$ & BR DFANBSB TQ & $\begin{array}{c}\text { Textual (Contábil, Financeiro, } \\
\text { Pessoal, Periódicos, Relatórios, } \\
\text { Projetos, Atas, etc.), Cartografia e } \\
\text { Fotografia }\end{array}$ & $\begin{array}{l}\text { Indústria; Empresas; } \\
\text { Brasil República }\end{array}$ \\
\hline $\begin{array}{l}\text { Supremo Tribunal de } \\
\text { Justiça }\end{array}$ & BR RJANRIO BU & $\begin{array}{c}\text { Textual (Processos, Acórdãos, } \\
\text { Decisões, etc.) }\end{array}$ & $\begin{array}{l}\text { Judiciário; Brasil } \\
\text { Império; Brasil } \\
\text { República }\end{array}$ \\
\hline $\begin{array}{c}\text { Supremo Tribunal } \\
\text { Federal }\end{array}$ & BR RJANRIO BV & $\begin{array}{c}\text { Textual (Processos, Acórdãos, } \\
\text { Decisões, etc.) }\end{array}$ & $\begin{array}{l}\text { Judiciário; Brasil } \\
\text { República }\end{array}$ \\
\hline
\end{tabular}




\begin{tabular}{|c|c|c|c|}
\hline $\begin{array}{c}\text { Telecomunicações } \\
\text { Brasileiras Sociedade } \\
\text { Anônima }\end{array}$ & BR DFANBSB CZ & $\begin{array}{c}\text { Textual (Contábil, Financeiro, } \\
\text { Pessoal, Periódicos, Relatórios, } \\
\text { Projetos, Atas, etc.), Cartografia e } \\
\text { Fotografia }\end{array}$ & $\begin{array}{l}\text { Comunicações; } \\
\text { Empresas; Brasil } \\
\text { República }\end{array}$ \\
\hline $\begin{array}{l}\text { Tribunal do Comércio da } \\
\text { Corte }\end{array}$ & BR RJANRIO EI & $\begin{array}{c}\text { Textual (Processos, Acórdãos, } \\
\text { Decisões, etc.) }\end{array}$ & $\begin{array}{l}\text { Judiciário; Brasil } \\
\text { Império; Brasil } \\
\text { República }\end{array}$ \\
\hline $\begin{array}{l}\text { Vara Cível do Rio de } \\
\text { Janeiro }\end{array}$ & BR RJANRIO CG - CP & $\begin{array}{l}\text { Textual (Processos, Acórdãos, } \\
\text { Decisões, etc.) }\end{array}$ & $\begin{array}{c}\text { Judiciário; Brasil } \\
\text { Império; Brasil } \\
\text { República }\end{array}$ \\
\hline $\begin{array}{c}\text { Vara de Fazenda Pública } \\
\text { do Rio de Janeiro }\end{array}$ & BR RJANRIO D4 & $\begin{array}{c}\text { Textual (Processos, Acórdãos, } \\
\text { Decisões, etc.) }\end{array}$ & $\begin{array}{l}\text { Judiciário; Tributário; } \\
\text { Brasil República }\end{array}$ \\
\hline $\begin{array}{c}\text { Vara Federal do Rio de } \\
\text { Janeiro } \\
\end{array}$ & BR RJANRIO D8 & $\begin{array}{c}\text { Textual (Processos, Acórdãos, } \\
\text { Decisões, etc.) } \\
\end{array}$ & $\begin{array}{l}\text { Judiciário; Brasil } \\
\text { República }\end{array}$ \\
\hline Vice-Reinado & BR RJANRIO D9 & $\begin{array}{l}\text { Textual, Cartografia, Iconografia, } \\
\text { etc. }\end{array}$ & $\begin{array}{l}\text { Agrário; Comércio; } \\
\text { Brasil Colônia }\end{array}$ \\
\hline Visconde de Cairu & BR RJANRIO R7 & $\begin{array}{c}\text { Textual (Diários, Anotações, } \\
\text { Cartas, Projetos, Requerimentos, } \\
\text { Publicações, Periódicos, etc.) e } \\
\text { Cartografia }\end{array}$ & $\begin{array}{l}\text { Pensamento Econômico; } \\
\text { Brasil Império }\end{array}$ \\
\hline
\end{tabular}

Fonte: BRASIL. Ministério da Justiça. Arquivo Nacional. Sistema de Informações do Arquivo Nacional. Rio de Janeiro: Arquivo Nacional. Disponível em: <http://www.sian.an.gov.br/>, acesso em: 01/10/2017.

\section{Arquivo Nacional: casa dos historiadores da Economia}

Um dos documentos mais utilizados pelos pesquisadores dedicados à História Econômica dos períodos colonial e imperial é, sem dúvidas, o inventário post-mortem. Através dele, é possível realizar profundas investigações sobre os barões do café, os homens livres pobres e mesmo os escravos. Certamente que esta espécie documental, de tipo textual, é uma das mais procuradas no Arquivo Nacional pelos historiadores. É importante lembrarmos que o Arquivo Nacional não possui um Fundo específico de inventários, pois eles estão distribuídos em vários, unificados pela série "Inventários", disponível para pesquisa na base de dados do Judiciário do Arquivo Nacional. ${ }^{2}$ Apesar disso, o Fundo do Juízo de Órfãos e Ausentes (BR RJANRIO ZN ZL ZM) concentra quase 19 mil exemplares destes documentos, dos mais de 23 mil apontados pela base dados.

Embora seja um documento cuja função fosse a de inventariar os bens de um determinado indivíduo após seu falecimento para que pudessem ser repartidos entre os herdeiros, o que poderia sugerir que sua aplicação se restringisse ao estudo dos afortunados de uma dada sociedade, a historiografia, desde meados dos anos 1980, quando começou a se utilizar desta documentação de modo mais sistemático, conseguiu superar a imagem de um Brasil polarizado unicamente entre o grande fazendeiro e os escravos, cristalizado pelo binômio

\footnotetext{
${ }^{2}$ Consultar em: http://www.an.gov.br/Basedocjud/MenuDocJud/MenuDocJud.php
} 
casa-grande e senzala (FREYRE, 2005). Hebe Mattos, em análise sobre a pobreza rural do município de Capivary, se utilizou dos inventários para identifica-la com a pequena produção de alimentos - nomeadamente a mandioca - realizada por unidades com menos de 410 pés plantados, em média, e poucos escravos - até 3 cativos (MATTOS, 2009, p. 65-71). Isto significa dizer que mesmo um "homem livre pobre" tinha bens a inventariar, tornando o inventário uma fonte útil para análise deste segmento da sociedade.

Mas, e os escravos? Antes de 1871, ano da aprovação da chamada Lei do Ventre Livre, não lhes era permitido possuir quaisquer tipos de bens. O costume, entretanto, se impôs e muito antes da referida lei, ainda no período colonial, já era possível observar os chamados "negros de ganho" espalhados pelas cidades, cuja única obrigação era a de pagar o jornal estabelecido pelos senhores. Embora muito mais pobres que os ditos "homens livres pobres", os escravos também tinham bens (VILLA, 2016). Mas não é aí que reside a validade do inventário como fonte para investigação dos escravos e da escravidão. A grande questão - que também é a maior perversidade de nossa história - é que os indivíduos escravizados eram bens e entravam no espólio do falecido(a).

Neste sentido, destacamos que o grande valor dos inventários como fonte para a História Econômica está em seu caráter massivo e reiterativo. Massivo porque, como já dissemos, é uma fonte que recupera dados e experiências de grupos sociais muito diversos. Reunindo os documentos disponíveis em um determinado ano é como pintar um quadro ou tirar uma foto, ou seja, nos dá um panorama de uma dada sociedade em um determinado momento. Reiterativo porque o falecimento de indivíduos é, obviamente, um fenômeno recorrente em qualquer época. Organizando-os em série ao longo do tempo, a fotografia ou o quadro ganham movimento, permitindo que se visualize algumas das transformações econômicas pelas quais uma sociedade passa (FRAGOSO; PITZER, 1988, p. 30).

Demonstrado, em linhas gerais, sua abrangência, é necessário que descrevamos esta documentação, complexa por definição. Segundo João Fragoso e Renato Pitzer, o inventário é uma fonte cuja estrutura interna se repete ao longo do tempo, passível de ser dividia em quatro seções: 1) abertura do inventário; 2) a avaliação dos bens; 3) os documentos comprobatórios da avaliação e das dívidas; e 4) a partilha dos bens (FRAGOSO; PITZER, 1988, p. 32).

É para a segunda e quarta sessões do inventário que direcionaremos nossa atenção. Isto porque a avaliação dos bens, junto de sua partilha, é de grande interesse para aqueles dedicados ao estudo das empresas. Aqui é necessário abrirmos um parêntese, pois entendemos empresa à 
maneira de Witold Kula: ela pode ser definida tão somente como uma unidade de produção que efetua uma exploração econômica a partir de determinadas escolhas disponíveis - e, portanto, limitadas - em um sistema econômico historicamente estabelecido (KULA, 1979, p. 25). Esta definição pode se adequar plenamente à análise de empresas pré-capitalistas, pois ressalta a necessidade de considera-las em seu contexto, o que elimina as possibilidades de projetarmos sobre elas uma racionalidade que não lhes pertence, como a racionalidade capitalista. Esta perspectiva afasta os historiadores das análises a-históricas desenvolvidas pelos economistas neoclássicos e pelos historiadores que se apropriaram desta teoria, que veem qualquer empresa, mesmo a feudal ou escravista, como se operassem sob diretrizes capitalistas (CARDOSO, 1979, p. 49).

A avaliação dos bens os dividem em três categorias: 1) os bens móveis, ou seja, utensílios domésticos, mobílias em geral, vestuários, joias e instrumentos de trabalho; 2) os bens imóveis, ou seja, as edificações e as culturas de uma fazenda, as terras e equipamentos como moinho ou moenda de um engenho; e 3) os bens semoventes, ou seja, aqueles que se movem por conta própria: os animais e os escravos (FRAGOSO; PITZER, 1988, p. 33). O fato de os escravos serem relacionados na mesma categoria dos animais já é um indicativo de determinados aspectos ideológicos que permearam a sociedade escravista brasileira até sua dissolução. Os escravos, especialmente após 1850, eram os elementos mais valiosos nos inventários e a riqueza de muitos fazendeiros era medida de acordo com o número de escravos que ele possuía. O nome, a origem - africana ou crioula, ou seja, nacional -, a cor, o sexo, o estado civil, a profissão - quando houver -, sua disposição para o trabalho e as condições de saúde são informações que podemos obter sobre os escravos a partir dos inventários. De maneira geral, os do sexo masculino eram maioria e seu preço era mais elevado que o das mulheres. Os jovens - aqueles que possuíam entre 15 e 40 anos - eram mais valorizados que as crianças e os velhos e, entre esses, os primeiros valiam mais que os últimos. Há, por fim, uma lista das dívidas passivas e ativas do inventariado.

Organizar a partilha dos bens é a função do inventário. É nesta sessão que se localiza o montante total de cada um dos tipos de bens que mencionamos acima. Da soma total do inventário se deduz as dívidas passivas e os custos do processo para que se inicie a partilha. Metade dos bens fica sob administração do cônjuge e os outros $50 \%$ são repartidos entre os herdeiros. Uma análise seriada das partilhas de bens pode nos informar, por exemplo, se a estrutura familiar dos escravos era respeitada ou se realizavam a separação entre mães/pais e filhos. 
Apresentada a fonte e algumas de suas potencialidades, nos cabe agora sugerir metodologias de uso. O primeiro ponto, como nos informam Fragoso e Pitzer, é com relação à representatividade do inventário. Recomenda-se, sempre, que se utilize todos os inventários de um determinado ano e que se repita esta operação em intervalos de tempo mais curtos possíveis - principalmente quando a série for mais longa -, isto quando não for possível lançar mão de todos os inventários relativos a todos os anos abrangidos pela pesquisa. Entretanto, este procedimento não assegura por si só a validade da fonte (FRAGOSO; PITZER, 1988, pp. 3637). Ao se estudar a população escrava de uma dada região, por exemplo, podemos confrontar a população escrava presente nos inventários com aquela registrada em censos de anos próximos aos de alguns inventários em termos de razão de sexualidade, perfil etário, origem, etc. Isto talvez ajude a vislumbrar o quão representativo da realidade aquele conjunto de inventários de que o pesquisador dispõe é representativo da realidade da qual ele deseja se aproximar.

Uma das grandes utilidades metodológicas do documento é a de se utilizar dele para vislumbrar o quão monopolizado eram os meios de produção. Se considerarmos que a sociedade brasileira do oitocentos é marcadamente agrária e escravista, os inventários se tornam uma excelente fonte para este intento.

Estudando o sistema escravista de Vassouras, Ricardo Salles identificou, através da análise seriada de inventários, que 9\% dos proprietários de escravos entre 1821-1880 - aqueles que possuíam mais de 100 em seus plantéis - controlaram quase 50\% do total de escravos empregados. Ao mesmo tempo, os que detinham até 19 escravos compunham 55\% dos proprietários e controlaram apenas $12 \%$ dos trabalhadores disponíveis em Vassouras ao longo do período considerado (SALLES, 2008, p. 155-161). Naturalmente, os que possuíam mais escravos eram também os que controlavam maior parte do solo agricultável das regiões cafeeiras e não há dúvidas que os inventários consultados por Salles demonstram isso, embora ele não tenha ressaltado este fato em sua análise. O controle dos meios de produção por parte dos maiores fazendeiros, tal qual demonstramos aqui, nos permite elucidar questões a respeito da capacidade de reprodução de suas empresas em relação às dos demais.

Embora alguns autores da NHE se empenhem em comparar o trabalho escravo com o assalariado, numa inútil tentativa de quantificar e comparar seus custos e sua taxa de retorno, para que possam, enfim, definir qual é mais rentável - dentro da referida lógica de empregar menos recursos para atingir um determinado fim -, é importante lembrarmos que no regime 
escravista o trabalho não tem preço, mas sim o trabalhador. Os escravos são como bens de capital, capitais fixos, pois o senhor deve alimentá-lo com ou sem trabalho para ser feito. Portanto, são parte dos meios de produção.

Mas não é apenas, também, por meio de métodos quantitativos que os inventários nos são úteis. Cabe aqui uma referência a uma sugestão metodológica qualitativa - proveniente de cruzamentos com outras fontes -, mas também aplicada à História Econômica. $\mathrm{O}$ poderoso Barão de Nova Friburgo, um dos homens mais ricos do Império à sua época, tem seu inventário depositado no Arquivo Nacional ${ }^{3}$. O cruzamento deste documento, de 1873, com as escrituras de compra da fazenda Aldeia, adquirida por ele em 1847, contribuem para que vejamos o quanto evoluiu seu patrimônio e a escala de operação da referida empresa. Nesta primeira data, a fazenda contava com 36 bestas, 25 gados e 100 porcos, além de possuir 200 mil pés de café e, pelo menos, 186 escravos (MARRETO, 2016, p. 2). O que se vê com o inventário é que a escala de produção da fazenda aumentou mesmo com um número menor de escravos, pois em 1873, quando fica pronto o inventário do Barão, morto em 1869, vemos que a mesma fazenda possui 600 mil pés de café - crescimento de 200\%. Além disso, possui também 57 bestas, 104 bois, 106 carneiros, 110 porcos cevados e mais 500 porcos no pasto. Tudo isto com "apenas" 150 escravos (MARRETO, 2016, p. 7). A multiplicação dos números de pés de café e de animais deixa poucas dúvidas sobre a ampliação da escala de operação da fazenda.

A abrangência temporal da Série Inventários abarca desde o século XVII (há inventários iniciados no ano 1687!) até meados do século XX. As condições dos exemplares costumam ser excelentes, mas todos só podem ser consultados fisicamente, nenhum está microfilmado ou digitalizado pela instituição. É possível buscar na base de dados as referências de localização do inventário e marcar a consulta, no balcão da Sala de Consultas, para um prazo de uma semana aproximadamente.

Outro exemplo de conjunto documental de grande valia para a História Econômica é o Fundo Junta do Comércio (BR RJANRIO, 7X), criado para preservar e organizar toda documentação de registros da Real Junta do Comércio, Agricultura, Fábricas e Navegação e parte da documentação do Tribunal da Relação. Este Fundo é importantíssimo no sentido de preservar valiosas informações sobre os negociantes e as empresas inauguradas por eles desde o período joanino. Seus registros dão conta das matrículas dos negociantes, dos sócios das

${ }^{3}$ BRASIL. Ministério da Justiça. Fundo Vara Cível do Rio de Janeiro. Série Inventários. Inventário postmortem/Partilha amigável do barão de Nova Friburgo. Caixa 2619, Galeria E, Id. 44.397, Notação 1171. Rio de Janeiro: Arquivo Nacional, 1873. 
empresas, bem como de seu capital, localização, atuação, atividades desempenhadas, etc. Algumas empresas forneciam estatutos e documentos contábeis.

Por conta de suas funções públicas relativas ao comércio, agricultura, fábricas e navegação, várias medidas de fomento à indústria e ao comércio estão fartamente documentadas nesse Fundo, o que inclui privilégios, isenções e concessões. Também estão incluídos nesse Fundo os regulamentos das atividades comerciais e fabris, decisões contra o contrabando, contra os desvios nas atividades comerciais (especialmente de importação, exportação e aquelas desempenhadas por estrangeiros), contra o tráfico negreiro, além de alguns processos de falências das empresas e das disputas judicias entre os comerciantes e suas respectivas casas comerciais.

A abrangência temporal deste Fundo se dá entre 1808 e 1850, quando é inaugurada a Junta Comercial (por força do Código Comercial). Ele está totalmente reproduzido em microfilmes digitalizados no formato $p d f$ e à disposição dos consulentes nos computadores da Sala de Consultas do Arquivo Nacional, assim como o seu catálogo impresso que é o principal instrumento de busca. Sua magnitude totaliza 37,49 metros de informação em 24 livros.

Eulália Lobo, no clássico História do Rio de Janeiro: do Capital Comercial ao Capital Industrial e Financeiro, se utilizou desta documentação, especialmente no que diz respeito às informações passíveis de quantificação. Como exemplo, podemos citar a tabela 2.3 , cujo título é "Número de Oficiais do Rio de Janeiro" (LOBO, 1978, p. 133-135). Ela é representativa da importância deste Fundo, pois suas informações ocupam três páginas quantificando os responsáveis por 55 tipos diferentes de oficinas (de Abridores de Metal até Violeiros, em ordem alfabética) em três anos selecionados: 1822, 1855 e 1850.

A partir de 1850, com a regulação do Código Comercial, a Junta do Comércio foi substituída pelo Tribunal do Comércio e pelas Juntas Comerciais provinciais. A criação desses órgãos fez parte do esforço para execução de um arcabouço jurídico-político modernizante que pretendia adequar as regras do jogo comercial brasileiro ao que mais avançado havia no centro do capitalismo. As Juntas Comerciais eram criadas aonde não havia condições de se estabelecer um Tribunal do Comércio. Mesmo com a criação destes órgãos, os Tribunais da Relação continuavam a existir, sendo instancia de apelação às decisões das Juntas; entretanto, os casos entre particulares e entre estes e o governo, bem como as questões referentes às companhias comanditárias e sociedades anônimas, deveriam ser dirigidas ao Tribunal do Comércio da Corte. 
O Fundo Junta Comercial do Rio de Janeiro (BR RJANRIO 46) inclui toda documentação registral do Tribunal do Comércio da Corte (que tem um fundo apenas para os seus processos: BR RJANRIO EI) e toda documentação da Junta Comercial do Estado do Rio de Janeiro no período abrangido, sendo importantíssimo como fonte quantitativa para apreendermos a dimensão e as tendências das economias carioca e fluminense ao longo do tempo. Os registros também podem ser utilizados qualitativamente pelas informações de contratos comerciais, escrituras públicas de dissolução, liquidação, partilha de sociedades e distratos entre particulares, assim como atas de assembleias e reuniões de conselhos das sociedades anônimas.

Neste fundo, as possibilidades para os historiadores da economia e das empresas é tamanha, que os próprios funcionários do arquivo indicam de pronto seu instrumento para todos aqueles que dizem estar interessados em registros empresariais ou de atividades econômicas no século XIX. O principal instrumento para localização dos registros neste fundo são os fichários 07 e 08, localizados no subsolo do Arquivo Nacional. Esta documentação abrange temporalmente entre 1850 e 1904, totalizando 92 livros de companhias e firmas com registro no Tribunal do Comércio (1850-1904) e 47 livros de firmas com registro na Junta Comercial do Estado do Rio de Janeiro (1891-1904). Os 139 livros não estão microfilmados ou digitalizadas, tendo de ser solicitados pelo número dos volumes e dos registros que o consulente procura.

Como exemplo, podemos citar o registro da firma comercial Antônio Martins Lage \& Filho no Livro 652, sob Registro 12184. Sua data de solicitação, deferida no mesmo dia, é de 02/01/1873. Nele consta um contrato simples entre Antônio Martins Lage e Antônio Martins Lage Filho de duração de cinco anos, tendo por fim "[...] o Comércio de Carvão de Pedra, Reboques, Trapiches e o mais que os sócios convier”. Outras informações são fornecidas, como o Capital Social de 400:000\$000 e a divisão hierárquica da empresa da qual Antônio Martins Lage era o sócio capitalista e Antônio Martins Lage Filho era sócio de indústria. ${ }^{4}$

Muitas das informações quantificadas e seriadas, ou mesmo qualitativas, fornecidas por Maria Barbara Levy (1977) e Eulália Lobo (1978), ainda na década 1970, são tomadas destes Fundos da Junta de Comércio e da Junta Comercial do Rio de Janeiro. As quantificações/séries de dados constituídas pelas autoras a partir desse fundo são referências, ainda hoje, para os

\footnotetext{
${ }^{4}$ BRASIL. Ministério da Justiça e Negócios Interiores. Junta Comercial. Livro 652, Registro 12184 (02/01/1873). Rio de Janeiro: Arquivo Nacional.
} 
historiadores da economia, da urbanização, industrialização, comércio, finança, etc. da Cidade do Rio de Janeiro.

O Fundo de Privilégios Industriais (BR RJANRIO PI) guarda os registros de patente pedidos entre 1857-1911, embora haja vários buracos de muitos anos sem qualquer pedido. A utilização destes documentos pela pesquisa histórica é bem recente e quase inédita, sendo necessário destacar o trabalho de Luiz Claudio Moises Ribeiro (1995), literalmente o pioneiro, pois contribuiu também para organizar esta rica documentação. As considerações feitas aqui dizem respeito aos pedidos de patente das máquinas de beneficiar café realizados entre 18761888, o que já compõe o vasto universo de 143 registros.

De maneira geral, os pedidos contêm informações valiosas, tais como o nome do inventor e do requerente - que pode ser o inventor ou um representante -, a cidade de onde partiu a requisição, além de um relatório sobre o funcionamento da máquina, a expectativa do inventor a respeito de seu potencial e, eventualmente, um desenho técnico semelhante a uma planta. Seu valor para estudo das técnicas e das tecnologias e, principalmente, da participação nacional e estrangeira em meio a este importante processo de inovação ainda está por ser descoberto.

Por meio desta documentação é possível descobrir quem eram estes inventores de máquinas e quais classes sociais eles estavam ligados/pertenciam, além de ser possível observar a participação de cada província do Império e cada estado da República no processo de inovação tecnológica do país, algo que pode também ser feito para cada cidade registrada no fundo como requerente de uma patente. Este acervo nos fornece a possibilidade de ultrapassar as interpretações ainda correntes de que na economia brasileira do oitocentos predominava um “projeto arcaico" baseado tão somente na obtenção de prestígio social por meio do controle de homens - escravos - e terras. As invenções demonstram como o dito setor "atrasado" da economia - porque estava vinculado à escravidão - dinamizava-se a partir do que havia de mais "moderno", numa integração dialética reveladora das formações sociais no Brasil.

Este fundo tem um catálogo digital em $p d f^{5}$ que, além das informações básicas dos pedidos, o classifica segundo a finalidade da patente pretendida: agricultura e indústria animal; alimentação; minas e metalurgia; máquinas e motores; transporte; instrumentos científicos e aparelhos calculadores; eletricidade; indústrias químicas; indústrias têxteis e vestuário; artes

5 Consultar em: <http://www.arquivonacional.gov.br/images/conteudo/servicos_ao cidadao/instrumentos-depesquisa/pdf/Privilgios-Industriais--Contedo-abril-13.pdf> . 
industriais e economia doméstica; indústrias diversas; construções; saneamento, iluminação, aquecimento e frio industrial; medicina, cirurgia, farmácia e profilaxia; arte militar e naval. A extensa variedade corresponde à magnitude deste conjunto documental de 9.301 dossiês de privilégios industriais, num total de 32,13 metros de documentos, nos quais estão contidos 22 mil desenhos e 619 amostras. Todo este acervo está, além de organizado, impecavelmente tratado e pronto para a consulta dos originais, com marcação no balcão da Sala de Consultas que demanda um prazo médio de uma semana.

Um Fundo organizado mais recentemente e que tem chamado a atenção dos historiadores da economia é o da Administração do Porto do Rio de Janeiro (BR RJANRIO 01). O Arquivo Nacional recebeu, ainda na década 1960, quando da constituição da Companhia Docas do Rio de Janeiro e da dissolução da autarquia Administração do Porto do Rio de Janeiro, toda documentação referente à atividade desta última desde, no mínimo, 1934. Entretanto, alguns documentos da concessionária anterior, a Companhia Brasileira de Portos, constam nesse fundo. Esta documentação ilustra bem a História Econômica do Brasil num tempo de mudanças aceleradas, não mais com o enfoque nos registros empresariais, mas sim a partir da agência econômica de um Estado que se construía como instrumento direto dos interesses da burguesia nacional e que documentava fartamente sua atividade econômica.

Neste Fundo podemos encontrar vasto e complexo conjunto documental, a maior parte diz respeito à força de trabalho mobilizada no porto do Rio de Janeiro. Os registros de pessoal e folhas de pagamentos são abundantes e também há documentação contábil, financeira, administrativa, política, legislativa, periódica e técnica. Por conta dessa diversidade, o instrumento do Fundo aponta para uma tipologia vasta: textual, cartográfica (plantas e mapas) e iconográfica (fotografias e desenhos).

Este fundo já tem um instrumento em $p d f^{6}$ disponível no Sistema de Informações do Arquivo Nacional, onde a busca é fácil e instintiva. Sua abrangência temporal, teoricamente, é de 1934 a 1950, mas é possível encontrar documentação produzida até a década de 1960 e é raro encontrar documentação (exceto legislação) antes da década de 1920. O Ministério dos Transportes depositou no Arquivo 304 maços que foram restaurados e organizados em 154 unidades de arquivamento, segundo a ordem de conteúdo, tipologia e assunto, montando aproximadamente 14 metros de documentação.

\footnotetext{
${ }^{6}$ Consultar em: 〈http://imagem.sian.an.gov.br/anexos/sian/referencias/17102012142242.pdf〉 .
} 
Mesmo antes da organização, pequena parte desta documentação já havia sido utilizada por Lérida Polvoleri em sua tese de doutorado (2001). Entretanto, boa parte dela permanece ainda inexplorada. A História Econômica tem, ainda, uma grande lacuna, qual seja: explicar a atuação econômica direta do Estado no período em questão. Não há dúvidas de que este conjunto documental servirá para avançar o entendimento de uma atividade tão vital para economia brasileira neste momento de pronunciadas mudanças.

\section{Conclusão: a História Econômica reivindica o Arquivo Nacional}

Este texto possui duas proposições: 1) tornar-se uma forma de divulgação da amplitude e importância do acervo do Arquivo Nacional para a pesquisa em História Econômica; e 2) demonstrar aos novos historiadores que a escrita da história depende fundamentalmente do apoio de instituições arquivísticas e semelhantes, uma vez que os documentos são nossa matéria-prima. Sua publicação ocorre logo após assistirmos, atônitos, a perda do mais valioso acervo de ciências sociais e naturais de nosso país, o do Museu Nacional. As razões para o incêndio, do fatídico dia 2 de setembro do corrente ano, já são conhecidas: a absoluta negligência do poder público para com a Universidade Pública e a produção científica e cultural de nosso país. Somos frequentadores, usuários e consulentes do Arquivo Nacional, sentimos em nosso cotidiano de trabalho as dificuldades que tem sido impostas e, às duras penas, superadas pelos seus abnegados funcionários. Advogamos que o melhor da História Econômica no Brasil contou, decisivamente, com os subsídios de informações tomadas nas fontes do Arquivo Nacional e reiteramos a necessidade de não permitirmos que o mesmo aconteça.

Com este intuito, demonstramos que pesquisas clássicas da historiografia se utilizaram da vasta documentação que se encontra disponível, até hoje, nesta instituição. A importância dos historiadores da economia, tanto na organização do acervo, quanto na demanda por seus serviços, é evidente. Também apontamos para o manancial de possibilidades que constituem os Fundos, Séries, Coleções, etc. sob guarda do Arquivo Nacional. Desde aquelas fontes documentais já muito utilizadas, mas ainda não esgotadas, até um sem-número de caixas, maços, livros, tubos, etc. totalmente inexplorados e prontos para tornaram-se vasto arsenal empírico a serviço dos historiadores da economia.

Conclamamos os novos historiadores a habitarem a Sala de Consultas do Arquivo Nacional, assim como chamamos a sua atenção para a História Econômica como ferramenta 
única, que associa longa duração e síntese para entender processos tão gerais, quanto as especificidades várias. Diante do pessimismo embasado e motor do crescimento deste campo, como o de Eulália, ou do exagero, supostamente coveiro, como o de Fragoso e Florentino, a História Econômica tem se renovado nas duas últimas décadas, com pesquisas sólidas e, muitas vezes, baseadas nos acervos do Arquivo Nacional.

\section{Referências}

BRASIL. Ministério da Justiça. Arquivo Nacional. Sistema de Informações do Arquivo Nacional. Rio de Janeiro: Arquivo Nacional. Disponível em: 〈http://www.sian.an.gov.br〉. Acesso em: 01 out. 2017.

CARDoso, C.; PÉREZ BRIGNOLI, H. Métodos da história. Rio de Janeiro: Graal, 1981. Agricultura, escravidão e capitalismo. Petrópolis: Vozes, 1979.

CHALHOUB, S. Visões da liberdade: uma história das últimas décadas da escravidão na Corte. São Paulo: Companhia das Letras, 1990.

CIPOLLA, C. Introdução ao estudo da história econômica. Lisboa: Edições 70, 1993.

FONTANA, J. El futuro de la historia económica. Reflexões sobre a História Econômica, São Paulo, n. 1, 2012.

FONSECA, M. O.; JARDIM, J. M. Estudos de usuários em arquivos: em busca de um estado da arte. Datagramazero, Rio de Janeiro, v. 5, n. 5, 2004.

FRAGOSO, J.; FLORENTINO, M. G. A história econômica: balanço e perspectivas recentes. In: CARDOSO, C. F.; VAINFAS, R. (Org.). Os domínios da história. Rio de Janeiro: Campus, 1997.

FRAGOSO, J.; PITZER, R. R. Barões, homens livres pobres e escravos: notas sobre uma fonte múltipla: inventários post-mortem. Revista Arrabaldes, Rio de Janeiro, n. 2, 1988.

FREYRE, G. Casa-grande \& senzala. São Paulo: Global, 2005.

GOMES, Â. C.; VAINFAS, R. Entrevista com Eulália Lobo. Estudos Históricos, Rio de Janeiro, v. 5, n. 9, p. 84-96, 1992.

HOBSBAWM, E. Sobre história. São Paulo: Companhia das Letras, 2013.

LEVY, M. B. História da Bolsa de Valores do Rio de Janeiro. Rio de Janeiro: IBMEC, 1977.

LOBO, E. História do Rio de Janeiro: do capital comercial ao capital industrial e financeiro. Rio de Janeiro: IBMEC, 1978. 
MARRETTO, R. M. O Barão de Nova Friburgo e a administração da Fazenda Aldêa: redes de sociabilidade no contexto da segunda escravidão (1849-1874). In: ENCONTRO DA ANPUHRIO, 7., 2016. Anais... Nova Iguaçu: UFRJ, 2016.

MATTOS, H. Ao sul da história: lavradores pobres na crise do trabalho escravo. Rio de Janeiro: FGV, 2009.

POVOLERI, L. M. L. O porto do Rio de Janeiro na estratégia do desenvolvimento da relação capitalista no Brasil: economia e política de transporte no primeiro governo Vargas (1930-1945). 2001. Tese (Doutorado em História Social) - UFRJ, Rio de Janeiro, 2001.

PRADO, C. História econômica do Brasil. São Paulo: Brasiliense, 1972.

KULA, W. Teoria econômica do sistema feudal. Lisboa: Presença, 1979.

RIBEIRO, F. A arquivística como disciplina aplicada no campo da Ciência da Informação. Perspectivas em Gestão \& Conhecimento, João Pessoa, v. 1, n. 1, p. 59-73, jan./jun. 2011. Disponível em: 〈http://periodicos.ufpb.br/ojs2/index.php/pgc >. Acesso em: 15 jun. 2017.

RIBEIRO, L. C. M. Ofício criador: invento e patente de máquina de beneficiar café no Brasil (1870-1910). Dissertação de Mestrado. São Paulo: USP, 1995.

SÁ NETTO, R. O império brasileiro e a Secretaria de Estado dos Negócios da Justiça. Rio de Janeiro: Arquivo Nacional, 2011.

SALLES, R. E o vale era o escravo. Rio de Janeiro: Civilização Brasileira, 2008.

LOPES, C. A. Acesso à informação pública para a melhoria da qualidade dos gastos públicos: literatura, evidências empíricas e o caso brasileiro. Cadernos de Finanças Públicas, Brasília, v. 1, p. 5-40, 2007.

TOMICH, D. A escravidão no capitalismo histórico: rumo a uma história teórica da segunda escravidão In: MARQUESE, R.; SALLES, R. (Org.). Escravidão e capitalismo histórico no século XIX: Cuba, Brasil, Estados-Unidos. Rio de Janeiro: Civilização Brasileira, 2016.

VILLA, C. E. V. Ao longo daquelas ruas: a economia dos negros livres em Richmond e Rio de Janeiro, 1840-1860. Jundiaí: Paco, 2016. 